\title{
Studies on Physio Chemical Properties of Fly Ash for their Effective Alkali Activation
}

\author{
Revathi $^{1}$, Jeyalakshmi ${ }^{1 *}$ Rajamane ${ }^{2}$, Sivasakthi $^{1}$, Dhinesh $^{3}$ \\ ${ }^{1}$ Department of Chemistry, SRM University \\ ${ }^{2}$ Centre for Advance Concrete Research (CACR), SRM University \\ ${ }^{3}$ Scientific Officer, Centre for Advance Concrete Research (CACR), SRM University
}

Received: November 05, 2015; Accepted: November 25, 2015; Published: December 15, 2015

*Corresponding author: Jeyalakshmi R, PhD, Professor, Department of Chemistry, SRM university, Kattankulathur, 603203, India, Tel: 94-441-0732-1;

E-mail: rajyashree64@gmail.com

\begin{abstract}
Alkali activation of fly ash with proper mix design and correct formulations can exhibit very good strength and chemical resistance and other potentially valuable characteristics similar or even better than conventional Portland cement. Various geo polymeric products is not difficult to achieve on a laboratory scale by optimization of process conditions, the ability to understand the flow ability, repeatability using variable material sources, control the setting process have always present to be issues in large scale production. A study was conducted on leaching of fly ash hybrid activator solution namely $\mathrm{NaOH}, \mathrm{Na}_{2} \mathrm{SiO}_{3}$, for preparing geo polymer. Geo Polymer (GP) concrete was made with the addition of organic admixture, Sodium naphthalene formaldehyde sulphonate, Cetyl Tetra Ammonium Bromide, Modified polycarboxylate super plasticizers by varying the dosage from $0-2 \%$ by keeping the Liquid/Solid as 0.45 . The specimens were cured for $70 \mathrm{C}$ for 24 hours. Flow ability for concrete were studied. Microstructure of the mortar was studied by FTIR and SEM/EDAX. The Compressive strength of the mortar in the order 30 Mpa was achieved with good flow property by the addition Modified Poly Carboxylate (MPC) and the zeta potential value was found to be similar in the order of control specimen $(-17.4 \mathrm{mv})$
\end{abstract}

Keywords: Geo Polymer; Fly Ash; SEM; XRD; EDAX; EDXRF, Compressive Strength; Super Plasticizer; Zeta Potential; And FTIR

\section{Abbreviations}

SEM: Scanning Electron Microscopy; XRD - X-Ray Diffraction; EDAX: Energy Dispersive X-Ray Spectroscopy; EDXRF - Energy Dispersive X-Ray Fluorescence; FT-IR: Fourier Transform-Infra Red Spectroscopy ; SP: Super Plasticizer; AAS: Alkali Activator Solution; ASTM: American Society for Testing and Materials; FA: Fly Ash; CTM: Compression Testing Machine; GSM: Geo polymer Source Materials; FAGP: Fly Ash Based Geo polymer

\section{Introduction}

World's Ordinary Portland cement industry production increases with the increasing demand of building industry which is crossing a million tons per year. At the same time fly ash, an industrial byproducts from coal based thermal power plant, which is available abundantly are underutilized worldwide consumption is about $20-30 \%$ of the generated fly ashin cementious products, construction areas such as highway road bases, grout mixes, stabilizing clay based building materials [1-5]. It has tremendous potential applications of new areas in recent years [6]. One of the best ways is to synthesize, geo polymer a binder made by alkali-activated solution because of its low-cost, environment-friendly, energy-saving and resource-recycling benefits.

The key processes involved in the synthesis of geo polymers are: (a) Dissolution of fly ash or similar alumino-silicate precursors to provide the $\mathrm{Al}$ and all or part of the Si constituents needed. (b) hydrolysis reaction to generate aluminum and silicate species and finally (c) condensation of these species and/or silicates from the activator to build up geo polymeric network structures. Geo Polymers (GP) with frameworks of $\left[\mathrm{SiO}_{4}\right]^{4-}$ and $\left[\mathrm{AlO}_{4}\right]^{5-}$ tetrahedral linked alternately by sharing all the oxygen atoms, are generally amorphous alumino silicates or semi-crystalline zeolites depending on the alkaline activator used in their manufactures and reaction conditions. The negative charge of $\left[\mathrm{AlO}_{4}\right]^{5-}$ tetrahedron on skeleton is balanced by extraframework cations of $\mathrm{Na}^{+}, \mathrm{K}^{+}$and $\mathrm{Ca}^{2+}$ ions.[7] Corresponding to different $\mathrm{Si} / \mathrm{Al}$ ratios, the geo polymers are composed of network structures of polysialate $(-\mathrm{O}-\mathrm{Si}-\mathrm{O}-\mathrm{Al}-\mathrm{O})$, polysialate siloxo (-O$\mathrm{Si}-\mathrm{O}-\mathrm{Al}-\mathrm{O}-\mathrm{Si}-\mathrm{O}-$ ), and polysialate disiloxo (- O -Si- O- $\mathrm{Al}-\mathrm{O}$ -Si- O-Si- 0).

The compressive strength and the workability of geopolymer concrete are influenced by the proportions and properties of the constituent materials that make the geopolymer paste. The available literature results have shown the following: [5, 8-11]

- Higher concentration (in terms of molar) of sodium hydroxide solution results in higher compressive strength of geo polymer concrete.

- Higher ratio of sodium silicate solution-to-sodium hydroxide solution ratio by mass, results in higher compressive strength of geo polymer concrete.

- The slump value of the fresh geo polymer concrete 
increases when the water content of the mixture increases. Super plasticizers may assist in improving workability.

- As the $\mathrm{H}_{2} \mathrm{O}$-to- $\mathrm{Na}_{2} \mathrm{O}$ molar ratio increases, the compressive strength of geo polymer concrete decreases.

The interaction of various process parameters, nature of admixtures on the compressive strength and workability of Geo polymer products are complex and hence final Geo polymer products exhibit different performance properties viz. high compressive strength, high thermal resistance, low shrinkage\& low thermal conductivity, high level of resistance to a range of different acids and salt solutions etc. It is also important to note that all Geo polymer products will result all of these properties or in other words, no single formulation that can optimize all the properties. Hence formulations recipes are required to tailor made Geo polymer mixes to attain the required specifications and technical performance. This will be possible only with thorough understanding of the raw material reactivity, chemistry, role of admixtures and reaction conditions.

The chemical admixture especially, high range water reducing admixtures commonly known as Super plasticizers have become essential component in ordinary Portland cement concrete. The commercial super plasticizers viz., sulphonate lignin, Sulphonate Naphthalene Formaldehyde (SNF), Sulphonate Melamine Formaldehyde (SMF), and poly carboxylates which are used in the production of Portland cement Concrete where dispersion of cement particles by electrostatic repulsion through adsorption process enhance ethe workability, giving high performance and improve durability. The mechanism and working nature of super plasticizers in OPC have been well reported in literature [12-14]. Such type of chemical admixtures does not work in Geo polymer system because of high alkaline conditions. ${ }^{[15]}$ The effect of third generation SP such as vinyl co polymers, poly acrylate co polymers along with modified form of melamine, naphthalene, polycarboxylate ester based on alkali activated slag and fly ash based have been reported [16-18]. It was found that addition of $\mathrm{N}$-based SP improved the workability up to $2 \%$ mass of binder without affecting the strength. Studies on evaluation of PC based SP on fly ash Geo polymer showed appreciable reduction in the strength around 20 to $35 \%$ with reference to original concrete. To ensure uptake of Geo polymer production at larger scale in the construction industry, research is needed in the critical area of suitable admixture for improving workability and durability.

Hence the present study, Physio chemical characteristics of raw materials used for geo polymerization reactions, microstructure of Geo polymer products, effect of water reducing admixtures on performance have been studied.

\section{Materials and Methods}

\section{Fly Ash}

Class F Fly Ash sample collected from Thermal Power Plant, Gummidipoondi, India, used as a Geo Polymer Source Material (GSM) The chemical composition of the low lime fly ash is determined by EDXRF analysis (Bruker) and is summarized in Table 1.

\section{Activator}

Sodium silicate solution was used as an alkali activator solution. ( $15 \% \mathrm{Na}_{2} \mathrm{O}, 33 \% \mathrm{SiO}_{2}$ and $52 \% \mathrm{H}_{2} \mathrm{O}$ ) The starting sodium silicate solution modulus was 2.0 and it was further adjusted by adding lye $(50 \% \mathrm{NaOH})$.

\section{Super plasticizers (SP)}

Naphthalene based compound namely, Sulphonated Naphthalene Formaldehyde Condensate (SNF)a second generations Super plasticizers, Modified Polycarboxylate Ester (MPC), a third generation SP and Cetyl tetra ammonium bromide (CTAB) are used in the present study. The physio-chemical properties are listed in Table. 2

\section{Preparation of Alkali Activator Solution:}

The commercially available $50 \%$ sodium hydroxide solution (i.e., Caustic lye) was mixed with distilled water in a closed container, the temperature measured by using Infrared thermometer was about $42^{\circ} \mathrm{C}$. Therefore, prepared sodium hydroxide solution was kept for $24 \mathrm{hrs}$ in order to bring down to room temperature and mixed with Sodium Silicate Solution of molar ratio 2.0, then stirred well for homogeneous mixing.

\section{Mixing, Casting and Curing:}

The materials were weighed accurately using digital electronic weighing balance. Sand and Fly Ash (Geo polymeric source material, GSM) were dry mixed for about 3 minutes in a digital mortar mixer till a uniform mix is achieved. Then, the AAS was poured into it and the mixing continued for further 7 minutes. SP's dosage were varied from $0.5 \%, 1 \%, 1.5 \%, 2.0 \%$ by mass of fly ash and the whole mix was blended for 4 min with the speed of $300 \mathrm{rev} / \mathrm{min}$. The mix proportions of mortar specimen are given in Table 3 . The fresh mix was then placed in to plastic cylindrical moulds of size $50 \mathrm{~mm}$ diameter x $100 \mathrm{~mm}$ height in three equal layers and compacted using a laboratory vibrator. After $24 \mathrm{hrs}$ of casting, the cylindrical moulds, containing the geo polymer mortar matrix, were kept for heat curing at $60^{\circ} \mathrm{C}$ for a period of $24 \mathrm{hrs}$ in a hot air oven. Then specimens were allowed to cool to room temperature before demoulding operations.

Table 1: Chemical composition of low lime fly ash is presented.

\begin{tabular}{|c|c|c|c|c|c|c|c|}
\hline $\begin{array}{c}\text { Component } \\
\text { (wt. \%) }\end{array}$ & $\mathrm{SiO}_{2}$ & $\mathrm{Al}_{2} \mathrm{O}_{3}$ & $\mathrm{CaO}$ & $\mathrm{Fe}_{2} \mathrm{O}_{3}$ & $\mathrm{~K}_{2} \mathrm{O}$ & $\mathrm{MgO}$ & $\mathrm{Na}_{2} \mathrm{O}$ \\
\hline FA & 47.55 & 33.45 & 2.099 & 10.17 & 1.65 & 0.005 & 0.015 \\
\hline
\end{tabular}


Table 2: Properties of SP's are shown.

\begin{tabular}{|c|c|c|c|c|c|}
\hline Superplasticizersa & Chemical base & Appearance & $\mathrm{pH}$ & Specific gravity & Solid content \\
\hline SNF & $\begin{array}{l}\text { Sodium naphthalene } \\
\text { formaldehyde sulphonate }\end{array}$ & Dark brown liquid & 7 & $1.2-1.5$ & $40-42 \%$ \\
\hline СТАВ & Cetyl Tetra Ammonium Bromide & White powder & $5-7$ & 1.5 & $38-40 \%$ \\
\hline MPC & Modified polycarboxylate & Colorless liquid & $3-4$ & 1.4 & $42-45 \%$ \\
\hline
\end{tabular}

Table 3: Details of mixture proportions are presented.

\begin{tabular}{|c|c|c|c|c|c|c|}
\hline \multirow{2}{*}{ GP mix design } & \multicolumn{3}{|c|}{ Mortar mix design } & \multicolumn{3}{|c|}{ Activator solution } \\
\cline { 2 - 7 } & $\begin{array}{c}\text { Fly ash } \\
\text { (By Weight) }\end{array}$ & $\begin{array}{c}\text { Sand } \\
\text { (By Weight) }\end{array}$ & $\begin{array}{c}\text { AAS/FA } \\
\text { (By Weight) }\end{array}$ & $\mathrm{Na}_{2} \mathrm{O} / \mathrm{Al}_{2} \mathrm{O}_{3}$ & $\mathrm{H}_{2} \mathrm{O} / \mathrm{Na}_{2} \mathrm{O}$ & $\mathrm{Si}_{2} \mathrm{O} / \mathrm{Al}_{2} \mathrm{O}_{3}$ \\
\hline FAGP & 0.5 & 1 & 0.5 & 0.43 & 3.35 & 0.5 \\
\hline
\end{tabular}

\section{Test methodology}

X-Ray characterization studies using X Phillips pW 1710" $\left(\mathrm{Cu} \mathrm{K} \mathrm{K}_{\alpha}=1.54178\right)$ and XRD pattern is shown in Fig 1. Micro structural characterization has been done by Scanning Electron Microscopy (Bruker) and FT-IR by KBr pellet technique (Perkin Elmer). The workability of fresh geo polymer concrete mixtures was tested by Slump test following ASTM: C1437. Flow of fresh geo polymer mortars was measured in accordance with ASTM C1437-07 to determine workability loss of fresh concretes. The consistency of the mixes was measured using a Vicat needle as described in ASTM C191-08. Malvern Zetasizer (Nano series) was used to measure the zeta potential with 0.5 weight $\%$ of Geo polymer matrices in deionized water against the standard potassium tungsto -silicate solution and calculations were made through Zetasizer software. The compressive strength test was performed on the specimens on 3, 7 and 28 days, with a loading rate of $0.33 \mathrm{MPa} / \mathrm{s}$ in a Controls CTM machine. Average of 3 test results was taken for calculations.

\section{Results and discussion}

\section{Mineralogical studies of source material}

$\mathrm{X}$-ray diffraction pattern analysis of fly ash contain mineral phases like quartz (PDF\#46-1045), magnetite, mullite (PDF\#851456), anorthite, hematite (PDF\#88-2359), and other minerals. Amorphous content in the fly ash has notbeen quantified from XRD. The glassy phase content of fly ash was determined by dissolving $1 \mathrm{~g}$ of it in $100 \mathrm{ml}$ of HF(1\%) acid -(Arjunan's method) with constant stirring for $6 \mathrm{hrs}$ [19]. Dried samples $\left(110^{\circ} \mathrm{C}\right)$ were weighed and the content of glassy phase was determined by weight loss. HF dissolve the glassy phase of fly ash, while crystalline phases (usually qurartz, mullite, haematite and magnetite) remains intact. In our study, the total quantity of $\mathrm{SiO}_{2}$ was found to be $48 \%$ wherein amorphous content was $35 \%$. Which are essentially required for the initiation step of the geo polymerization process, yielding higher amounts of reactive $\mathrm{SiO}_{2}$ and $\mathrm{Al}_{2} \mathrm{O}_{3}$ and further to combine during the agglomerate phase.

\section{FTIR Spectrum of source material}

Fig.2 depicts the FTIR spectrum of FA, activated fly ash with (FAGP1) and without addition of SP (FAGP). The original Fly ash precursor contains both 'active' and 'inactive' bonds indicating their reactivity in the alkaline solution. The active sharp absorption band at around $1093 \mathrm{~cm}^{-1}(\mathrm{~s})$ related to asymmetric stretching of $\left(\mathrm{Si}, \mathrm{Al}^{\mathrm{IV}}\right)-\mathrm{O}-\mathrm{Si}$ in glass and partially overlapped by phases of mullite and quartz. The vibrational frequency at 990 $\mathrm{cm}^{-1}(\mathrm{~m})$ which corresponds to the asymmetric stretching of $(\mathrm{Si}, \mathrm{Al}$ IV)-O-Si in amorphous glasses which could be composed of higher $\mathrm{Al}$ concentration. The vibrational frequency at $793 \mathrm{~cm}^{-1}(\mathrm{w})$ and $555 \mathrm{~cm}^{-1}(\mathrm{w})$ was assigned to the symmetric stretching of Si-O-Si in quartz and $\mathrm{Al}^{\mathrm{VI}}$ symmetric stretching of $\mathrm{Al}-\mathrm{O}-\mathrm{Si}$ in Mullite or Mullite like structure. These bonds are said to be 'inactive'. FTIR spectrum of activated fly ash (FAGP) exhibiting the broad peak at around $1000-1100 \mathrm{~cm}^{-1}(\mathrm{~b})$ are attributed to T-O asymmetric stretching vibrations and represent the fusion of both Al-O and $\mathrm{Si}-\mathrm{O}$ symmetric stretching. The lower wave numbers are related to a larger extent of aluminium incorporation into the silicate backbone. The broad bands at about $3453 \mathrm{~cm}^{-1}(\mathrm{~b})$ and1643 $\mathrm{cm}^{-}$

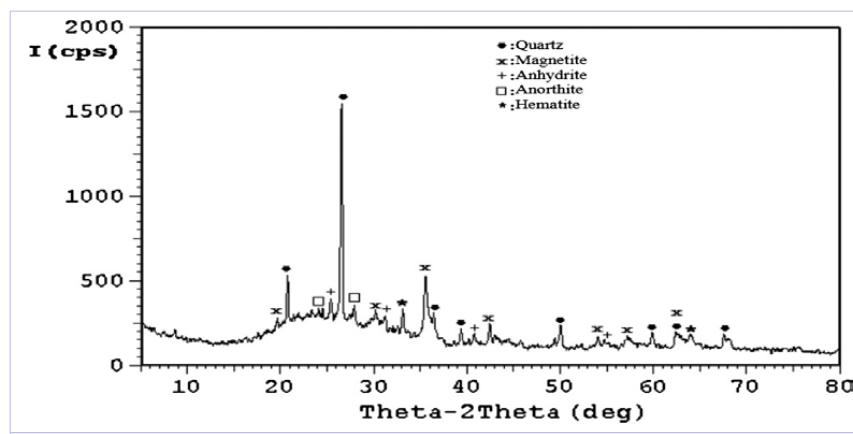

Figure 1: XRD pattern for fly ash (Indian).

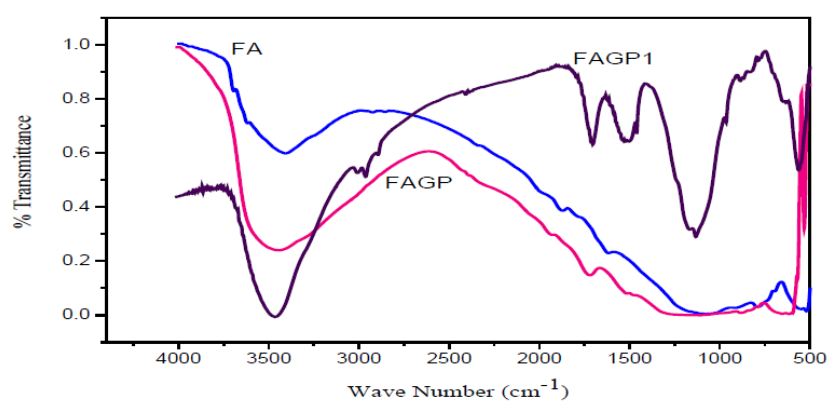

Figure 2: FT-IR spectrum of Fly ash and fly ash geopolymer. 
${ }^{1}(\mathrm{~m})$ correspond to stretching vibrational frequency and bending vibrational frequency of adsorbed water molecule formed during the reaction. Also it has an $\mathrm{Si}-\mathrm{O}-\mathrm{Al}$ stretching vibration at 775 $\mathrm{cm}^{-1}$ and Si-O-Al bending vibration at $433 \mathrm{~cm}^{-1}[19]$. Therefore, the original silicate and or/alumina-silicate structure in raw material have been significantly depolymerized through leaching during alkali activation. The FTIR of FAGP1 spectra, the additional peaks around $2924 \mathrm{~cm}^{-1}$ reflected the presence of aliphatic $-\mathrm{CH}$ bond and doublet at around $2360 \mathrm{~cm}^{-1}$ correspond to $-\mathrm{NH}_{2}$ group which are due to the organic amino admixture added in the specimen.

\section{Effect of addition of SP on workability of activated fly ash concrete}

The slumps of the activated fly ash concrete with the addition of different SP are shown in the Fig.3. The increase in relative slump was found to be $40 \%, 35 \%$ for the concretes added with MPC and SNF respectively whereas for CTAB additions do not show any improvement in slump. This could be due to the instability of the compound at high alkaline medium ( $\mathrm{pH}$ level of AAS is around 13) $[18,20]$. Generally, most of the commercially available SP to OPC was found to be not suitable for alkaline activator of fly ash. In the case of MPC, existence of several lateral chains in its structure results in steric repulsion that compensates the tendency of particles to form complexes, therefore their plasticizing ability would be greater than SNF based SPs.

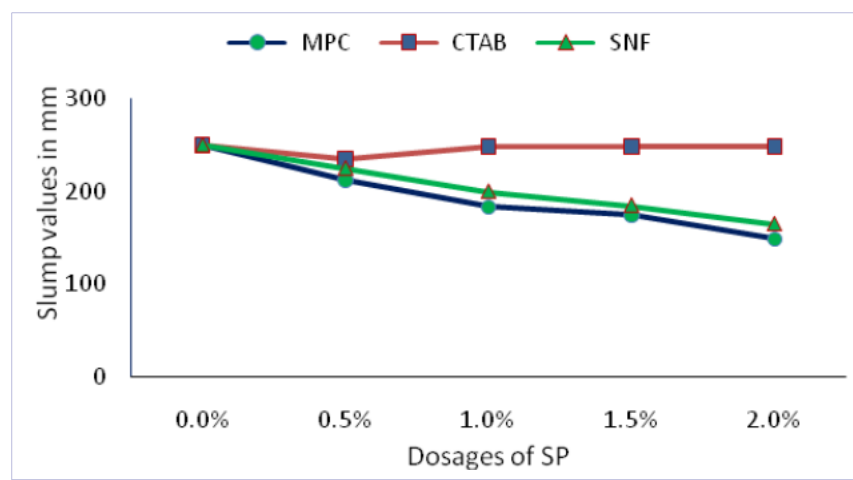

Figure 3: Slump of fly ash based geopolymer with addition of SP.

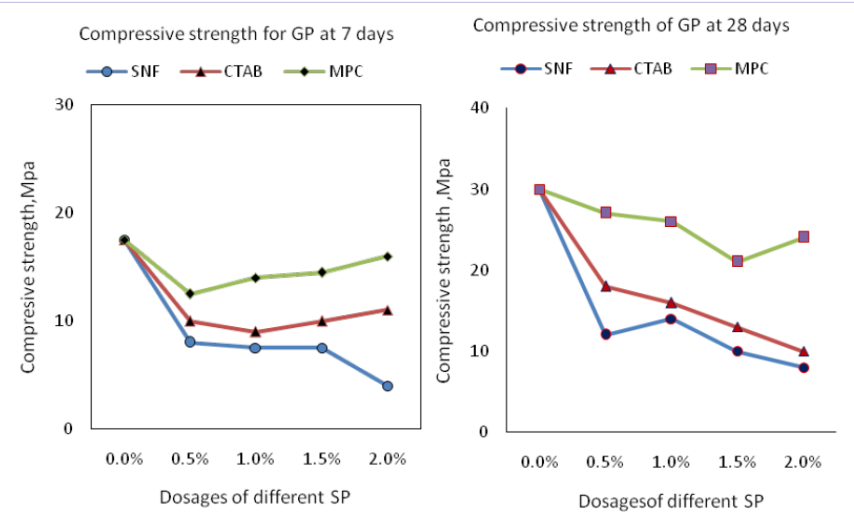

Figure 4: Compressive strength of Fly ash GP (a) 7 days (b) 28 days.

\section{Compressive strength}

The compressive strength of mortar mixes with and without addition under heat curing conditions for different curing days have been carried out. Control specimens, FAGP showed gradual increase from $5 \mathrm{MPa}(3 \mathrm{~d}$ ), $17 \mathrm{Mpa}(7 \mathrm{~d})$ to $30 \mathrm{MPa}$ at 28 days. The compressive strength of the mortar at 7 days and 28 days with and without using different SPs is shown in Fig. 4(a) \& 4(b). Generally, additions of SP in cement matrix do not affect the strength significantly. In present study, the compressive strength of the mortar by using all types of SPs (i.e. SNF, CTAB and MPC based SPs) was decreased with respect to that of the control mortar. The decrease in compressive strength was 57\%, 48\% and $10 \%$ for the mortars with SNF, CTAB and MPC respectively. The SNF and CTAB have shown the reduction in compressive strength may be due to the instability of these SPs in a very high alkaline medium (pH level of AAS is around 13) but MPC based SP's has shown higher plasticizing (workability) and less negative effect on the compressive strength compared to $\mathrm{N}$ and M based SPs [20].

\section{Zeta potential (६)}

Zeta potential is a scientific term for electrokinetic potential [21]. It is a measure of the magnitude of the electrostatic or charge repulsion/attraction between particles, and is one of the fundamental parameters known to affect stability.

Fly ash contains a reactive silicate and aluminate groups on its surface it has negative zeta potentials. During the geo polymerization reaction, activator solution having $\mathrm{OH}-$ ions react with the aluminate species on the surface of fly ash forming $\left[\mathrm{Al}(\mathrm{OH})_{4}\right]^{-}$and with silicate species form either $\left[\mathrm{SiO}(\mathrm{OH})_{3}\right]$ or $\left[\mathrm{SiO}_{2}(\mathrm{OH})_{2}\right]^{2-}$, thereby establishment of negatively charged double layer. Further $\mathrm{Na}+$ ions of the alkaline activator react to form a sodium alumino silicate gel layer [22]. There by smaller negative values will be expected.

In the case of FAGP, the small zeta potential $(-15.4 \mathrm{mv})$ was observed, this is due to the accumulation of more $\mathrm{Na}+$ ions in the double layer while forming gel resulted in a decrease of zeta potential and higher compressive strength. The addition of MPC in FAGP (-17.6 mv) shows small change in zeta potential and It is also reflected in compressive strength.

With the addition of SNF and CTAB in FAGP leads to more negative zeta potential such as $-44.6 \mathrm{mv}$ and $-35.5 \mathrm{mv}$ respectively. The agglomerated fly ash particles are found to be destabilizes by the addition of CTAB and SNF as seen from the more negative values, which also evident from their compressive strength [23].

\section{Morphology}

The morphology of fly ash precursors observed from SEM photograph showed that fly ash particles are appeared to be spherical as thin walled hollow sphere with the size of 1 micron Fig 6(a). SEM picture of alkali activated fly ash mortar after 28 days of curing time Fig.6 (b) clearly showed that dense gel formation over the surface of fly ash with fewer unreacted particles might be the presence of mullite or quartz phase. 


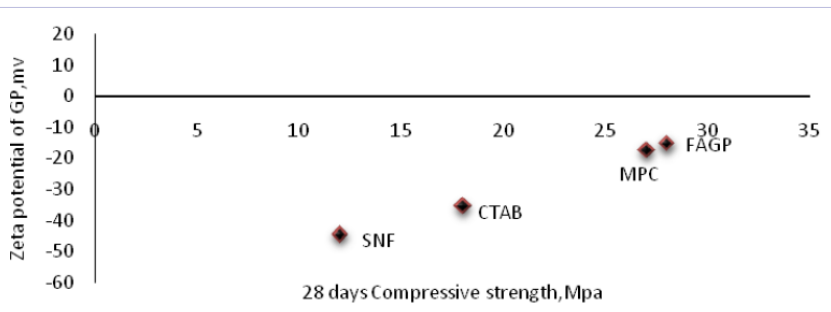

Figure 5: Zeta potential of fly ash and geopolymer suspensions in water.
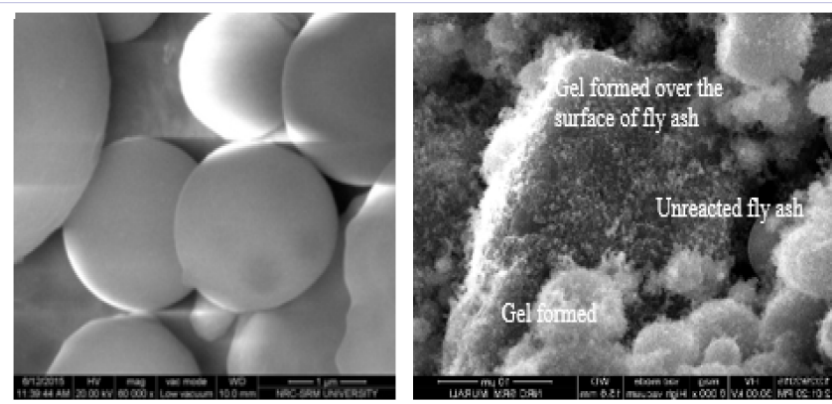

Figure 6: SEM image of (a) original fly ash (b) FAGP.

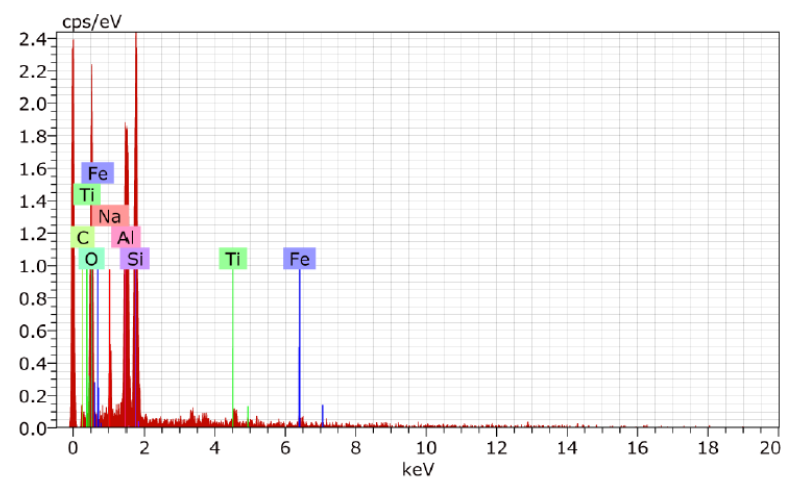

Figure 7: EDAX of FAGP.

\section{Conclusion}

Fly ash activated by hybrid mixture of sodium hydroxide and sodium silicate solution was found to be appropriate for the geopolymerisation reaction with acceptable compressive strength $(30 \mathrm{MPa})$.The adsorption of organic admixture in the alkali leaching fly ash reaction might contribute the improvement of flow properties of the precursors evident from the slump test to the concrete mix. Further to note MPC based SP to the GP concrete mix restore the compressive strength at the satisfactory level.The microstructure of geopolymer formed in our mix design studied by SEM/EDAX revealed that the compact dense microstructure of the matrix with lesser number of unreacted fly ash particles. The FTIR spectra showed the prominent $\mathrm{Si}-\mathrm{O}-\mathrm{Si}$ vibartion $\left(990 \mathrm{~cm}^{-1}\right)$ indicate the degree the geopolymerisation. The results from EDAX indicate that major components in GP paste were silicon and aluminum having $\mathrm{Si} / \mathrm{Al}$ ratio 1.5 . with small amount of sodium.

\section{Acknowledgement}

We gratefully acknowledge financial support from the SRM University and Department of Science and Technology (DST) under grant no DST/TSG/2012/20.

\section{References}

1. Joseph Davidovits. Geopolymer Chemistry and Applications: 3rd edition Geopolymer institute. 2011;4.

2. P Duxson, A Fernandez-Jimenez, JL Provis, GC Lukey, A Palomo, JSJ van Deventer. Geopolymer technology: the current state of the art. Journal of Materials Science. 2007;42(9):2917-2933.

3. A Fernandez- Jimenez, A Paloma, M Criado. Microstructure development of alkali activated cements descriptive model Cem Conc Res. 2005;35(6):1204-1209.

4. NP Rajamane, MC m Natarajon and R Jeyalakshmi. Pozzolanic industrial waste based geopolymer concretes with low carbon footprint. ICI Journal ,Special issue: Future Cement. 2014;88(7):49-68.

5. Hardjito D, Wallah SE, Sumajouw DM, Rangan BV. On the development of fly ash-based geopolymer concrete. ACI Mater J Am Concr Inst. 2004;101(6):467-472.

6. Blissett RS, Rowson NA. A review of the multi-component utilization of coal fly ash. Fuel. 2012:97:1-23.

7. Joseph Davidovitts, J Duxson, P Fernandez-Jimenez, A Provis, JL Luke. Geopolymers: Inorganic polymeric new materials. Journal of Thermal Analysis. 1991:37:1633-1656.

8. Brooks J, Johari M, Mazloom M. Effect of admixtures on the setting times of high-strength concrete. Cem Concr Compos. 2000;22(4):293-301.

9. Puertas F, Vázquez T. Early hydration cement Effect of admixtures superplasticizers. Mater de Constr 2001;51(262):53-61.

10. Chandra S, Björnström J. Influence of cement and super plasticizers type and dosage on the fluidity of cement mortars-Part I. Cem Concr Res. 2002;32(10):1605-1611.

11. Chandra S, Björnström J. Influence of superplasticizer type and dosage on the slump loss of Portland cement mortars-part II. Cem Concr Res. 2002;32(10):1613-1619.

12. Bakharev T. Geopolymeric materials prepared using class $\mathrm{F}$ fly ash and elevated temperature curing. Cem Concr Res. 2005;35(6):1224-1232.

13. Temuujin J, Riessen A van, MacKenzie KJD. Preparation and characterization of fly ash based geopolymer mortars. Const Build Mater. 2010;24(10):1906-1910.

14. Alaa M Rashad. A comprehensive overview about the influence of different admixtures and additives on the properties of alkaliactivated fly ash Materials and Design. 2014;53:1005-1025.

15. Hanehara S, Yamada K. Interaction between cement and chemical admixture from the point of cement hydration, absorption behaviour of admixture, and paste rheology. Cem Concr Res. 1999;29(8):11591165.

16. Zhang Z, Wang H, Provis J. Composition Design and Microstucture Characterisation of Calcined Kaolin based Geopolymer Cement. Sustainable Cement based Mater JL. 2010;47(3-4):271-275.

17. Bakharev T, Sanjayan J, Cheng Y-B. Effect of admixtures on properties of alkali activated slag concrete. Cem Concr Res 2000;30(9):13671374.

18. Palacios M, Puertas F. Effect of super plasticizer and shrinkage- 
reducing admixtures on alkali-activated slag pastes and mortars Cem Concr Res. 2005;35(7):1358-1367.

19. P Arjuan, MR Silbee, DM Roy. Quantitative determination of the crystalline and amorphous phases in low calcium fly ashes, in: Proceeding of the 10th International congress of the Chemistry of Cement. Gothenburg. Sweden. 1997;p.2-6.

20. Criado M, Palomo A, Fernandez-Jim enez A, Banfill P. Alkali activated fly ash: effect of admixtures on paste rheology. Rheol Acta. 2009;48(4):447-455.
21. M Nic, A Jenkins, J Jirat, B Kosata. Definition of electrokinetic potential in "IUPAC. Compendium of Chemical Terminology". 1997. ISBN0-9678550-9-8. doi:10.1351/goldbook

22. Chamila Gunasekara, David W Law, Sujeeva Setunge, Jay G Sanjayan. Zeta potential, gel formation and compressive strength of low calcium fly ash geopolymers. Construction and building materials. 2015;95:592-599.

23. TM Riddick. Control of Colloid Stability through Zeta Potential. ZETAMETER. 1968;1. 